\title{
A Method to Predict Rock Fracture with Infrared Thermography Based on Heat Diffusion Analysis
}

\author{
Nai-Fu Deng $\mathbb{D}^{1},{ }^{1}$ Lan Qiao, ${ }^{1,2}$ Qing-wen $L i \mathbb{D}^{1,2}$ Jia-Wang Hao $\mathbb{D}^{1},{ }^{1}$ and Shan $W u^{3}$ \\ ${ }^{1}$ State Key laboratory of High-Efficient Mining and Safety of Metal Mines, University of Science and Technology Beijing, \\ Beijing 100083, China \\ ${ }^{2}$ Beijing Key Laboratory of Urban Underground Space Engineering, University of Science and Technology Beijing, \\ Beijing 100083, China \\ ${ }^{3}$ Beijing General Research Institute of Mining and Metallurgy, Beijing 102628, China \\ Correspondence should be addressed to Qing-wen Li; qingwenli@ustb.edu.cn
}

Received 10 December 2020; Revised 18 January 2021; Accepted 15 February 2021; Published 28 February 2021

Academic Editor: Guozhong Hu

Copyright (C) 2021 Nai-Fu Deng et al. This is an open access article distributed under the Creative Commons Attribution License, which permits unrestricted use, distribution, and reproduction in any medium, provided the original work is properly cited.

\begin{abstract}
The forming of micro or mesocracks on rock surfaces is a symptom and precursor of the degradation of deep surrounding rocks under excavation. However, the direct detection or observation of these tiny developed cracks is not practical due to the limitation of current instruments which can only capture and recognize macrocracks. Therefore, many indirect detection ways are proposed to acquire some precautional signals and hereby forestall damage and failure of surrounding rocks. Infrared radiation (IRR) monitoring is one of the frequently used technologies. Current thermography derived from IRR can capture all temperature changes including the surrounding environment; this may influence the on-site judgement due to uncertainty or blur of generated temperature images. This paper proposes the "pseudothermography" under the true triaxial compressive test by combining the infrared radiation data and the heat diffusion theory. Our method evenly selects 25 small regions on the observed rock surface and uses the data obtained from these regions to derive the global temperature field which contains no uncertainty. By comparing our method with the real temperature field, the deduced diffusion model proposed in this paper can relatively reflect the real crack initiation under increasing loading. The experiment result proves that the attempt for the application of heat diffusion law is feasible to indirectly reflect the formation of micro and mesocracks and, ultimately, foresee the failure of the surrounding rock.
\end{abstract}

\section{Introduction}

Deep surrounding rocks are usually subjected to complex, nonisobaric, triaxial stress. Following the formation of new surrounding rocks under excavation, the horizontal stress concentration caused by horizontal unloading usually leads to rockburst, caving, and other destructive phenomena [1], which endangers the safety of construction. In the deep rock fracture study, Luong introduced an infrared monitoring method in 1990 to detect abnormal infrared radiation when cracks occurred [2]. Nowadays, infrared radiation detection, as a kind of noncontact monitoring means, has been widely applied to the study of rock fragmentation mechanism [35]. By acquiring the continuous variation of the infrared images obtained from an infrared camera, we can analyze the abnormal temperature changes and obtain a temperature distribution on the rock surface. Thus, the law of surface damage accumulation and crack development of rock mass can be known in advance to avoid such disasters.

In recent years, many researchers have used infrared technology to quantify the loading stage by dividing the infrared plots into several stages [6-8]. These research results provide robust evidence for the infrared detection of rock fractures. Researcher $\mathrm{Wu}$ and his leading team compared three forewarning methods of rock failure and concluded that infrared signals could be used to predict the failure of coal rocks and sandstones [9], the results also indicated that infrared forewarning came after the warning signals of acoustic emission and electrical resistance detection, which provided more reliable indicator to rock failure. Sun et al. also 
confirmed this in 2019 by performing experiments on a hard-rock pillar model and received the same outcome as the infrared radiation thermal survey might tell the fracturing of rock in the light of high stress [10]. As a result, infrared thermography has been shown to be a forewarning of rock failure. In 2002, scholar Lixin Wu and his team used infrared instruments to find out that shear failure and tensile failure of rocks were reflected as rising and falling, respectively, in the infrared temperature field [11]. Lixin $\mathrm{Wu}$ believed that if shear friction between cracks occurred in the course of rock mass collapse, the infrared radiation temperature was bound to increase; on the contrary, if the surface of the rock mass had tension-induced cracks or surface spallation, it would allow the temperature of infrared radiation to decrease. Therefore, the infrared monitoring method has good reliability in the study of the failure law of rocks.

The infrared will, however, not only measure the temperature change of the rock before failure due to the detection mechanisms of infrared instruments but also track the temperature changes for the environment. Therefore, there is normally a significant amount of noise on the edge of the initial infrared shot, which influences the engineering decision. In the past two years, scholars have made decent progress in the research of infrared monitoring technology $[8,12,13]$. However, limited by the instrument, infrared monitoring is inherited with several problems such as unclear images and local blurring around cracks; therefore, some researchers do not directly use infrared images but use the original image matrix data for image reconstruction [14-16]. Nevertheless, the reprocessing of the image matrix is usually followed by issues such as poor processing accuracy, resulting in obvious stratified temperature distribution and making it difficult to obtain the subtle variation of temperature.

A triaxial compression test of the fractured rock sample was performed in this paper based on the above issues to simulate the actual stress level of the underlying rocks after excavations through the release of unilateral horizontal axial stress, and infrared monitoring has been applied to observe the stress-unloading surface of the fractured rock samples during failure process. Influenced by the stress and the fracturing, the temperature of the rock surface will fluctuate spontaneously up and down. Changes in temperature within any dielectric substance will induce differences in temperature in the form of thermal diffusion (conduction) [17]; thus, to reduce ambient noise and local blurry issues with infrared thermography, this paper uniformly selects 25 clear regions without noise around the prefabricated fissure and generates an Average Infrared Radiation Temperature (AIRT) map based on the real observed temperature on these 25 selected regions. By introducing the heat diffusion equation, we deduce the change in the surrounding temperature dependent on 25 groups of actual temperature observed and obtain a clear global temperature distribution without blurring across the prefabricated fissure. Meanwhile, traditional infrared measurement instruments can barely capture sensitive changes in thermal diffusion, but by choosing a particular temperature shift step, the thermal diffusion equation can deduce minor temperature variance,

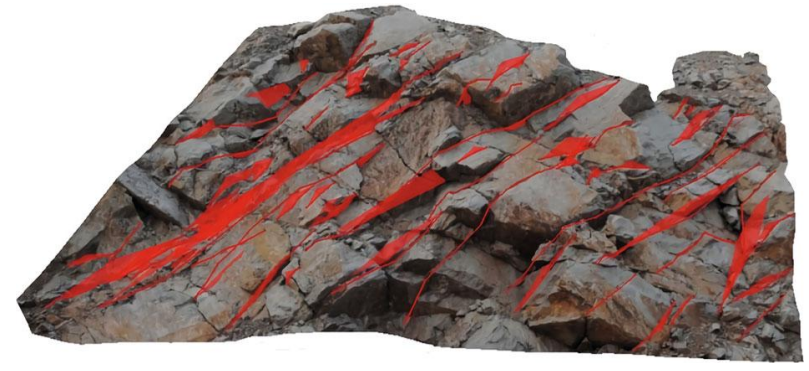

FIGURE 1: Natural cracks on the tunnel face onsite.

which can compensate for local fuzzy problems and reflect rock fragmentation reliably.

Therefore, the specific setting of the test and the basic principle of thermal diffusion will be described in detail in Section 2. In Section 3, the relationship between rock fracture and AIRT increment will be explored by analyzing the changes of 25 selected regions under three different confining stress. Section 4 will deduce the global surface temperature changes based on heat diffusion law and further analyze the relationship between rock fracture and temperature. The last section is a summary of the whole paper.

\section{The Introduction of Research}

2.1. Experimental Setting. This paper is aimed at studying the correlation between the failure law of the fracture surrounding rocks after excavation in a deep roadway and the infrared thermography data. Many scholars has studied a number of fracture rock samples with different precast fissures. Adams and Sines conducted experiments on brittle materials made from polymethylmethacrylate with embedded cracks at an angle of $20^{\circ}$ to $70^{\circ}$ [18]. In 1994, scholar Germanovich researched on the mechanisms of brittle rocks with preexisting cracks inclined to the compression axis under $30^{\circ}$ and $45^{\circ}$ [19]. Dyskin et al. conducted similar experiments on crackembedded rocks with $30^{\circ}$ and $45^{\circ}$ prefabricated cracks in 2003 [20]. Additionally, according to onsite investigation in Shanshan Island Gold Mine in Shandong, China, most natural cracks captured and synthesized by the ShapedMetrix 3D system on the tunnel face are at an angle of around $45^{\circ}$ (see Figure 1). Therefore, a standard cubic red sandstone sample of $150 \mathrm{~mm}$ is selected, and a "chord-shaped" prefabricated fissure crack is machined at an angle into a face of the block with a length of about $82 \mathrm{~mm}$ and a maximum depth of around $21 \mathrm{~mm}$ using a cutter shown in Figure 2. Besides, prefabricated fissure at an angle of $45^{\circ}$ ensures the same projection length of the prefabricated crack in the direction of $\sigma_{1}$. For the convenience of research, the two tips of the prefabricated crack are named tip No. 1 and tip No. 2. To focus on the study of the fracture characteristics of the key areas around the prefabricated crack and avoid the noise problem at the edge of the thermography, the infrared monitoring range of this paper is the red area (regions of interest) in Figure 2(b). Within the infrared monitoring area, 25 small regions are uniformly selected as the base point of the subsequent temperature diffusion research. The region location diagram is shown in Figure 2(c). 


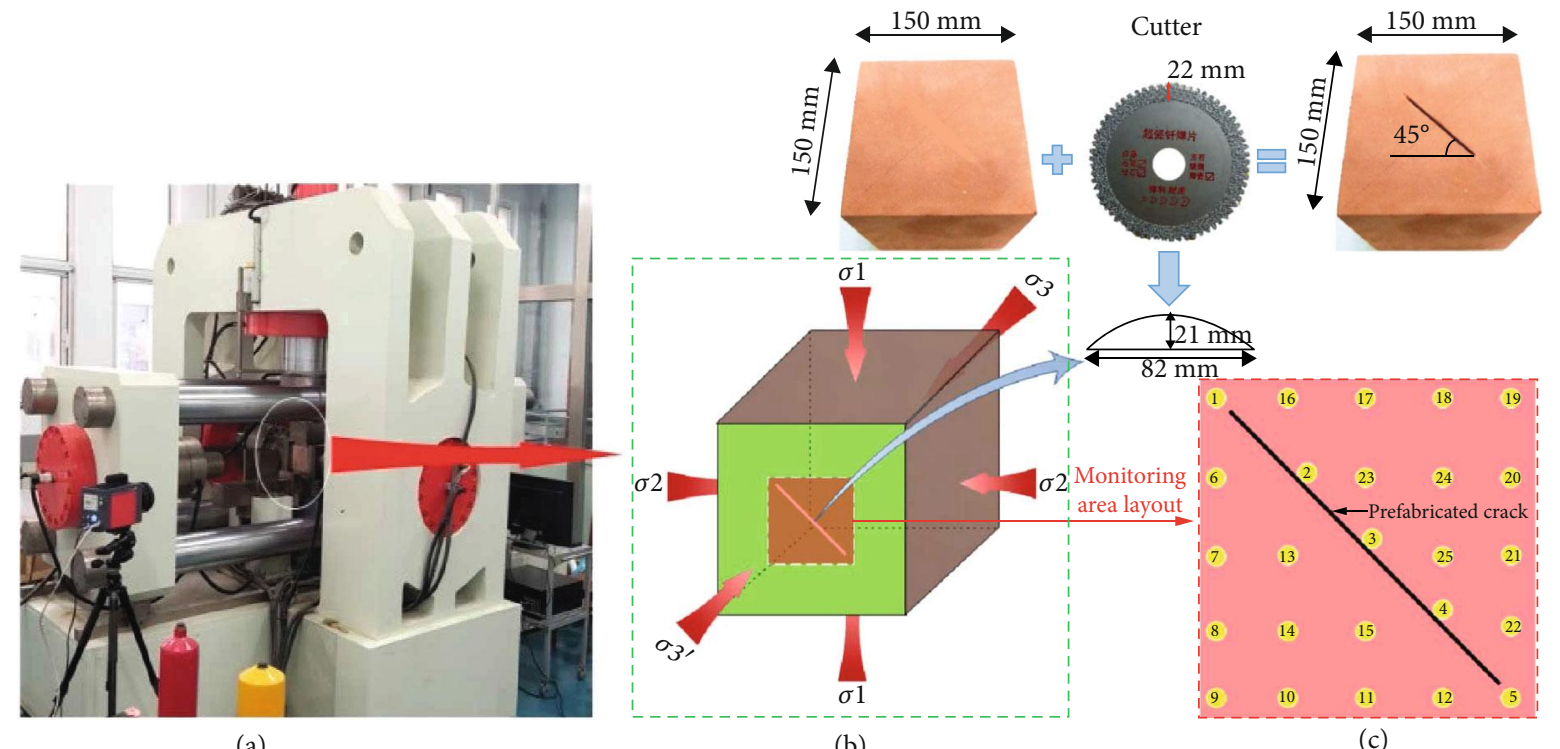

(a)

(b)

(c)

FIGURE 2: Distribution diagram of the prefabricated fissure and selected monitoring regions on red sandstones specimen.

At the beginning of the compression test, a $3000 \mathrm{~N} / \mathrm{s}$ loading rate is applied in three directions to load $\sigma_{1}, \sigma_{2}$, and $\sigma_{3}$ to the hydrostatic pressure state $\left(\sigma_{1}=\sigma_{2}=\sigma_{3}=\right.$ $2.5 \mathrm{MPa})$. Then, $\sigma_{3}$ ceases to be loaded, while $\sigma_{1}$ and $\sigma_{2}$ are continuously loaded to the preset surrounding pressure (14 $\mathrm{MPa}, 22 \mathrm{MPa}$, and $30 \mathrm{MPa}$, respectively). At this time, $\sigma_{2}$ has reached its preset geostress while $\sigma_{3}{ }^{\prime}$ is unloaded immediately to simulate the excavation of the tunnel. Finally, the machine continues to load $\sigma_{1}$ at a rate of $0.12 \mathrm{~mm} / \mathrm{min}$, and the infrared monitoring instrument starts to work and record the temperature change during loading until the rock sample fails.

2.2. Law of Heat Conduction. The heat diffusion (conduction) equation was first proposed by Fourier in 1822 [21]. The equation is written as follows:

$$
\frac{\partial C}{\partial t}=\Delta(D C)
$$

where $C(x, y, z, t)$ represents the temperature at a certain point in space at a certain time; $\partial C / \partial t$ represents the temperature gradient at a certain point in space; $\Delta$ is the Laplace Operator; $D$ is the thermal coefficient which depends on the thermal diffusion coefficient, density, and heat capacity of the material. According to the research of Sun et al. in 2016 [22], the thermal coefficient of red sandstones ranges between 0.5 and $2.5 \mathrm{~mm}^{2} / \mathrm{s}$; thus, this paper chooses $D=1.2$ $\mathrm{mm}^{2} / \mathrm{s}$ in Section 4 to do further research on the deduction of thermal diffusion.

The research object of thermal diffusion in this paper is the tunnel face formed by roadway excavation, and only the temperature change of the unloading surface of the fractured rock is observed in the experiment. Therefore, Equation (1) can be written in the following two-dimensional form:

$$
\begin{gathered}
\frac{\partial C(x, y, t)}{\partial t}=D_{x}(x, y, t) \frac{\partial^{2} C(x, y, t)}{\partial x^{2}} \\
+D_{y}(x, y, t) \frac{\partial^{2} C(x, y, t)}{\partial y^{2}}, \\
\left\{\begin{array}{l}
\left.C\right|_{x, y, 0}=\varphi(x, y, t) \\
\left.\partial C\right|_{x, y, 0}=\zeta(x, y, t) \\
\left.C\right|_{(x, y) \in \Omega}=0
\end{array}\right.
\end{gathered}
$$

where $D_{x}$ and $D_{y}$ are the thermal coefficient in $x$ and $y$ directions, respectively. Equation (2) is a second-order linear partial differential equation, and Equations (3) and (4) are the initial conditions and the boundary condition. The analytical solution for Equation (2) is [23]:

$$
C(x, y, t)=\frac{e^{-\left(\left(x^{2}+y^{2}\right) / 4 D t\right)}}{4 \pi D t}
$$

Known by Equation (5), the temperature will decrease as the diffusion distance and time increase, which obeys the common sense in real life.

The solution is an exponential equation which is not a conventional polynomial equation, so it is difficult to compute, especially in the need of thousands of times of iterative calculation by computers, because the exponential-form solution can greatly slow down the computation speed. Therefore, for partial differential equations, scholars usually use the finite difference algorithm to calculate the approximate numerical solution to replace the analytical solution and proceed to the intensive iterative calculation in computers. In this paper, the explicit difference algorithm is 


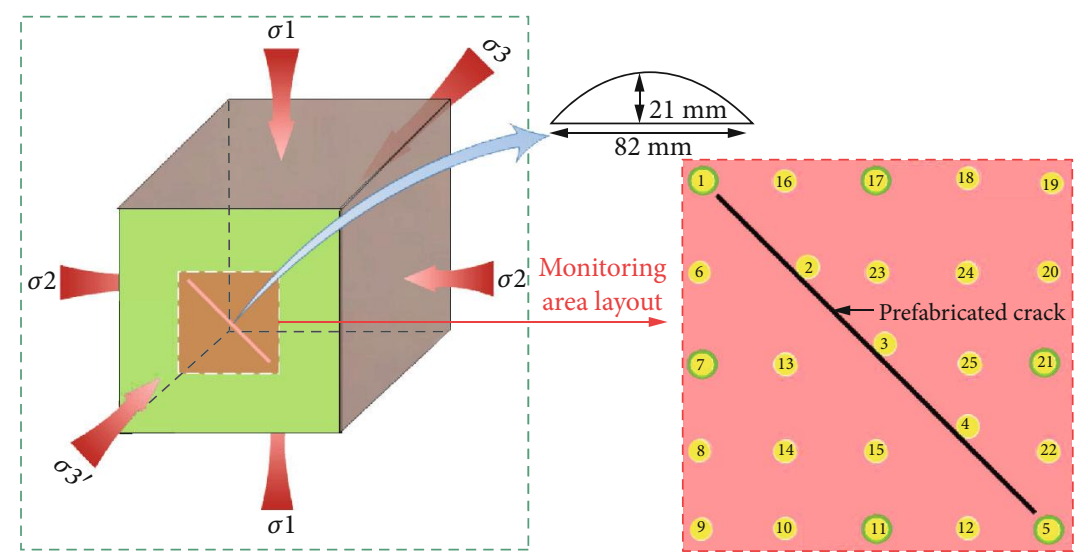

FIGURE 3: Layout of monitoring regions.

selected to solve Equation (2), and the finite-difference numerical solution can be written as follows [24]:

$$
\begin{aligned}
C_{i, j}^{t+1}= & C_{i, j}^{t}+r x\left(C_{i+1, j}^{t}-2 C_{i, j}^{t}+C_{i-1, j}^{t}\right) \\
& +r y\left(C_{i, j+1}^{t}-2 C_{i, j}^{t}+C_{i, j-1}^{t}\right),
\end{aligned}
$$

where $r x=D_{x} d t / d x^{2}, r y=D_{y} d t / d y^{2}, r x$, and $r y$ are the mesh ratio in $x$ and $y$ directions, respectively. Normally, the explicit difference equation can converge stably if the mesh ratio is less than 0.5 . Thus, this paper selects 0.1 as the mesh ratio to ensure enough precision in the calculation of Equation (2). In our research, MATLAB R2020a is selected to do the heavy computing task of heat transferring deduction. Based on the temperature changes of 25 discrete regions, the temperature changes around 25 regions are calculated and deduced, and then, the accumulation of the global damage and cracks on the rock surface is analyzed according to the deduced temperature changes.

\section{Analysis on Average Infrared Radiation Temperature (AIRT)}

Rock will deform and crack under triaxial compression, and the rock deformation and fracture are usually accompanied by the emission in energy, leading to the change in temperature which can be captured by infrared monitoring instrument. The occurrence of cracks and damage is represented as the abnormal temperature rise and drop on the real-time thermography; thus, through these abnormal temperatures, the law of crack propagation, deformation, and failure of rock can be intuitively observed. By obtaining the temperature data of 25 discrete regions in the real-time infrared temperature matrix, the AIRT increment can be obtained, and the AIRT-by-time and AIRT histogram can be plotted therewith. Therefore, the analysis of the crack regions and crack development trend is possible.

3.1. Analysis of AIRT Increment under $14 \mathrm{MPa}$ Confining Stress. As indicated in Figure 3, the 25 regions of interest are evenly distributed around the prefabricated fissure. C1 and C5 are selected as represented to be analyzed because these two regions are very close to the two tips of the prefabricated fissure where stress concentration may occur, former research has proved that "primary cracks" normally extended from the initial flaw due to stress concentration and intrinsic weakness [18-20]. Therefore, the two tips are more prone to fracture and accumulating energy and damage, which could lead to conspicuous temperature. Besides, to be representative, C7, C21, C17, and C11 are selected as the west end, east end, north end, and south end of the regions of interest. The selection of these four regions indicates no favor of any specific regions except the two tips as mentioned above, which can provide more general information to the analysis. Therefore, only these six specific monitoring regions are selected to demonstrate the plot of AIRT increment/stress-time under $14 \mathrm{MPa}$ in Figure 4. In addition, all strength and thermography data are attached in the supplemental file which provides all AIRT increment/stress-time curves under 3 kinds of confining stress.

Figure 4 plots the AIRT incremental changes over time and the stress-by-time curve of fractured rock samples under $14 \mathrm{MPa}$ confining stress at 6 specific monitoring regions $(\mathrm{C} 1$ C5 C7 C11 C17, and C21). According to the trend of the AIRT increment curve of six groups, there appear different levels of temperature drop and surge before reaching the ultimate stress (indicated as blue circles) except C17. This proves that large-scale fractures occur in different regions (only region $\mathrm{C} 17$ is an exception) of the rock surface before reaching the ultimate compression capacity, and this also foresees the impending failure of the rock.

Figure 5 is a three-dimensional histogram of temperature change before rock failure by importing AIRT increment data of 25 monitoring regions around the crack into MATLAB under $14 \mathrm{MPa}$ confining stress. The black line in each subfigure shows the approximate location of the prefabricated crack. By observing the increment change of AIRT before approaching the ultimate stress, it can be found that the temperature distribution near the crack is generally balanced and stable at $t=928.50 \mathrm{~s}$, and the highest temperature is at tip No. 2. Subsequently, the temperature fluctuates in a small range and gradually forms a step-like temperature distribution pattern around the crack $(t=931.51 \mathrm{~s})$. There is a 

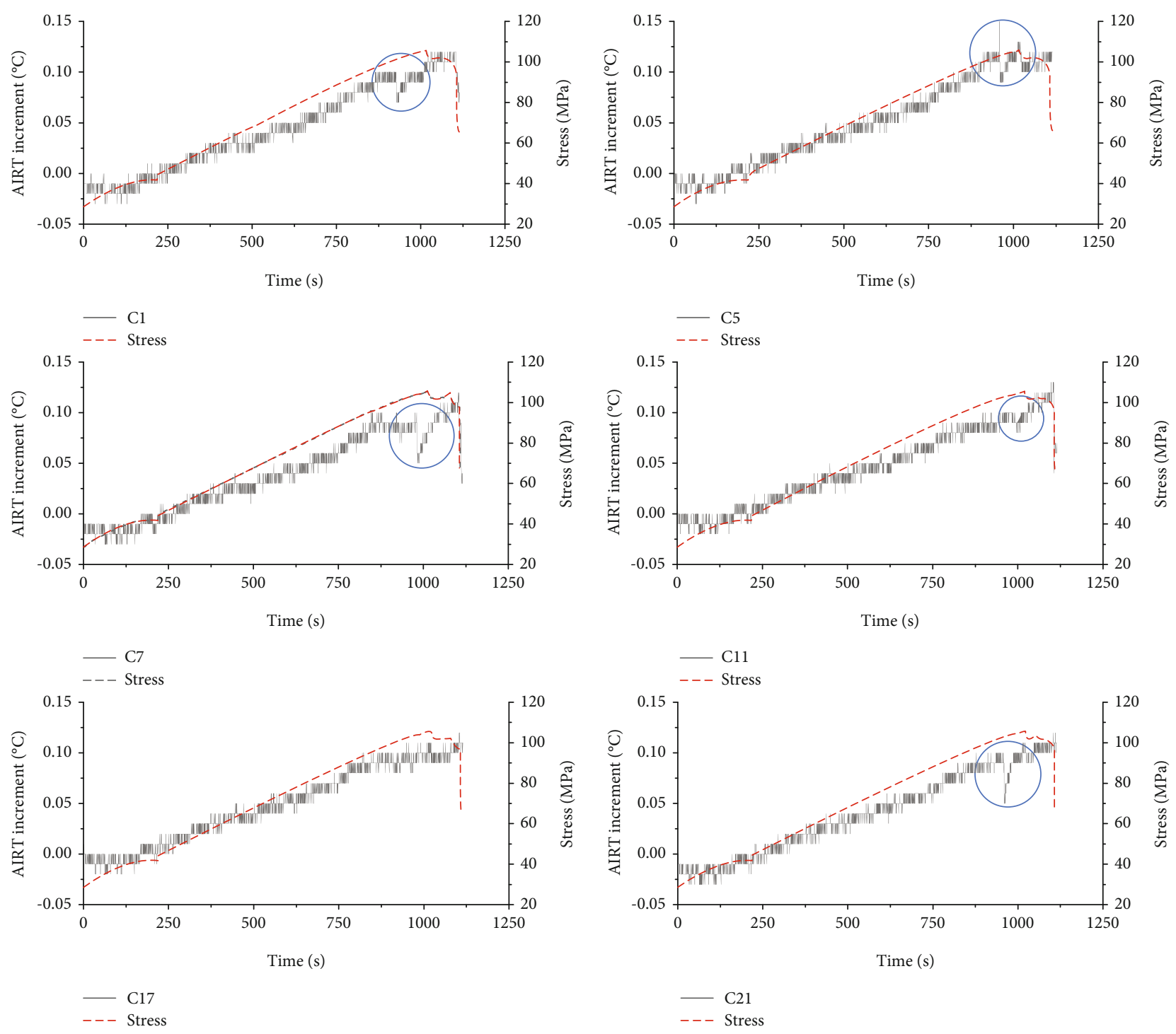

FIgURE 4: AIRT increment/stress-time under $14 \mathrm{MPa}$.

large degree of temperature rise in the region of C5 and C22, indicating that a significant local stress concentration phenomenon is formed at tip No. 2. After maintaining for $27 \mathrm{sec}-$ onds, a shear fracture occurred at tip No. 2, resulting in a sudden increase in temperature at region C5 $(t=958.80 \mathrm{~s})$. In few seconds of heat releasing at tip No. 2, presented as temperature decrease locally ( $t=960.91 \mathrm{~s})$, the temperature in the whole rock surface emerges a uniform distribution $(t=971.11 \mathrm{~s})$. Before approaching the peak stress, the temperature field presents a certain degree of irregular distribution $(t=1014.32 \mathrm{~s})$ due to the influence of the nonuniform stress field around the prefabricated crack.

By comparing Figure 4 with Figure 5, Figure 4 can present more intuitive variation characteristics of the temperature field before the verge of failure. Figure 5 shows that the region near tip No. 2 is a "fracture-prone area", presented as "slow undulated rising, sudden increase, sudden drop, and gradual climb-up". Figure 5 clearly shows that, with the gradual increase of external load, the shear stress field is grad- ually forming at the two sides of tip No. 2, and the energy gradually accumulates accompanied by temperature rise. Until the occurrence of shear fracture at tip No. 2, a large amount of elastic strain accumulated in the early stage is released rapidly, and "shear-type temperature" increases sharply at tip No. 2 (region C5), resulting in cracking and partial spalling of the rock surface.

3.2. Analysis of AIRT Increment under $22 \mathrm{MPa}$ Confining Stress. Figure 6 shows the AIRT increment change adjacent to failure around the prefabricated fissure under $22 \mathrm{MPa}$ confining stress. The temperature of the whole rock surface is generally higher on the left and lower on the right before failure. Especially, on the left-wing of the prefabricated fissure, because the two sides of the weak tip are prone to accumulate damage and generate cracks, the shear stress field firstly forms at tip No. 1 at $t=1053.30 \mathrm{~s}$. With the increase of external load, the shear stress field at tip No. 1 gradually expands downward along the weak joints and fissures of the rock 

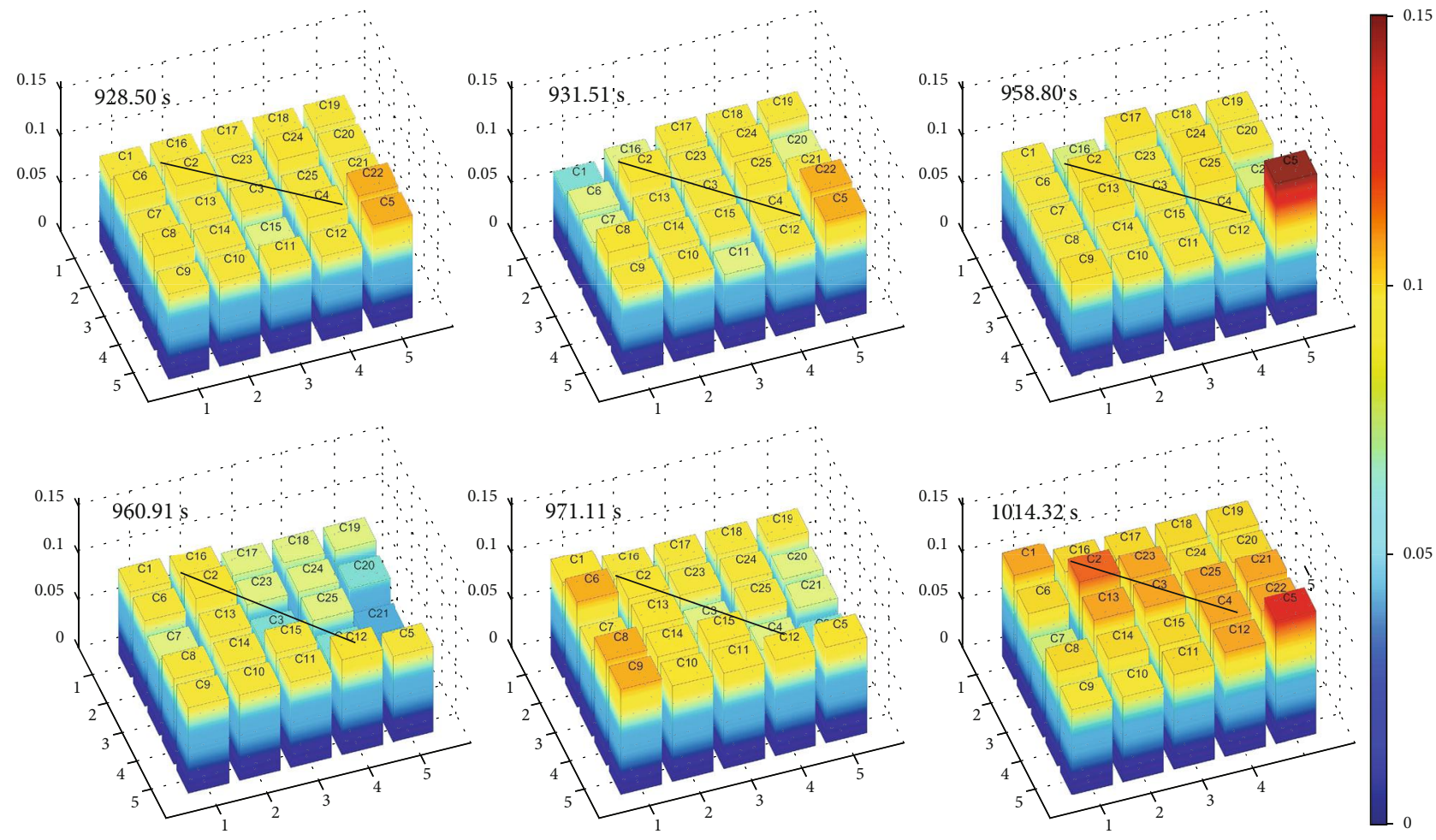

FIGURE 5: AIRT increment histogram under $14 \mathrm{MPa}$ before peak stress (Black line indicates the prefabricated crack), reading from left to right and then up to the bottom.
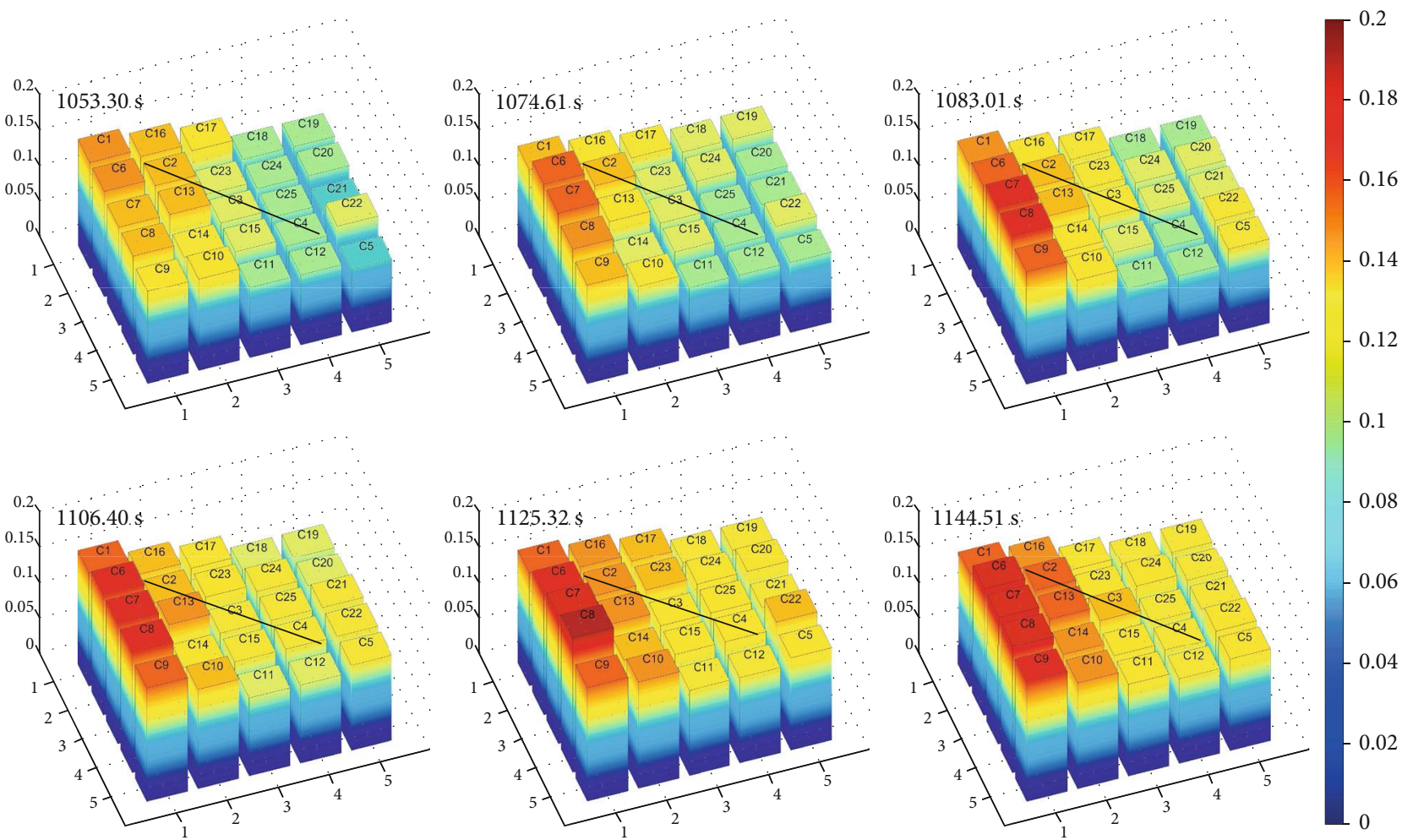

FIGURE 6: AIRT increment histogram under $22 \mathrm{MPa}$ before peak stress (black line indicates the prefabricated crack), reading from left to right and then up to the bottom. 

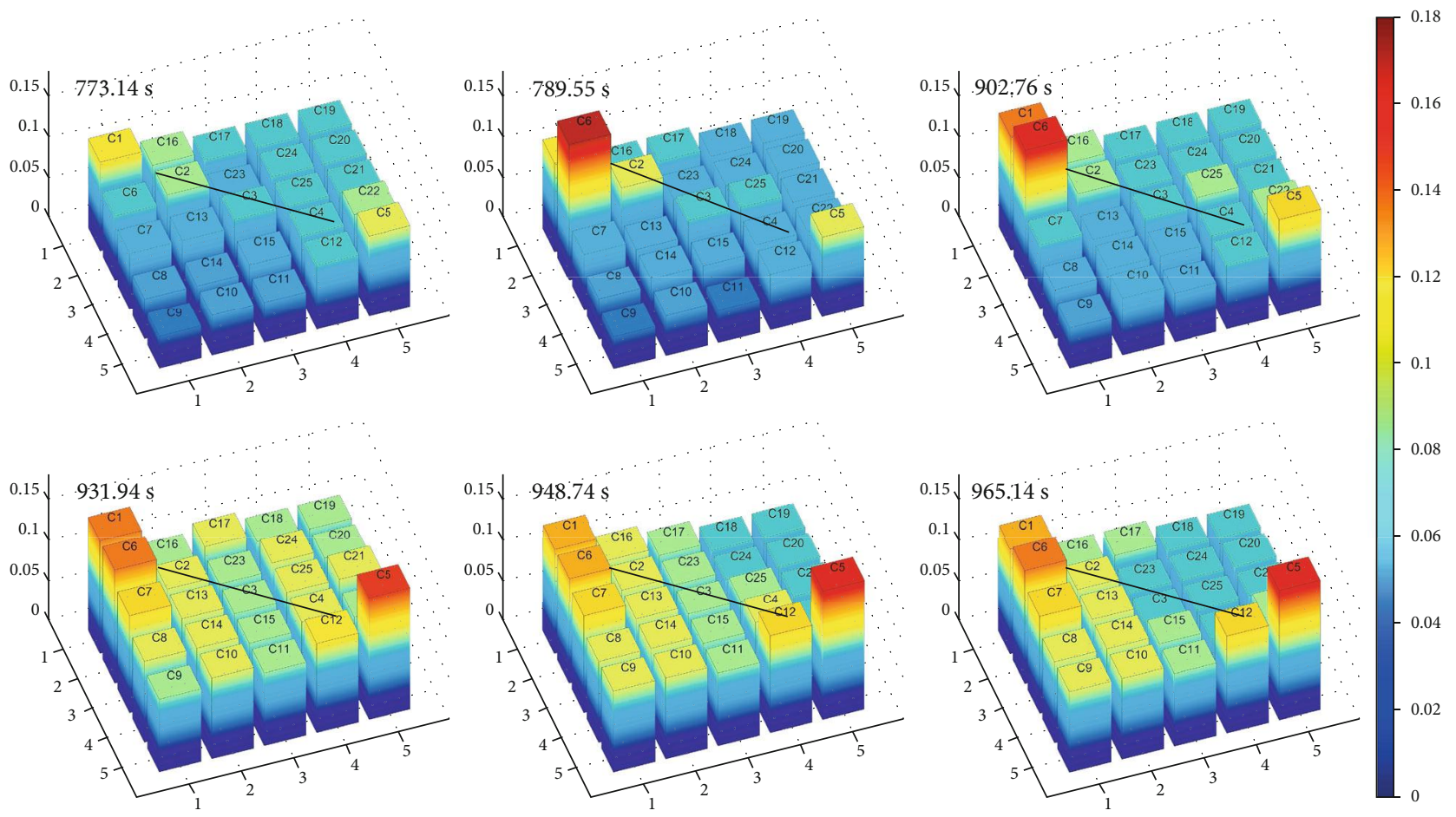

FIGURE 7: AIRT increment histogram under $30 \mathrm{MPa}$ before peak stress (black line indicates the prefabricated crack), reading from left to right and then up to the bottom.

block ( $t=1074.61 \mathrm{~s})$, resulting in the temperature field on the left side of the prefabricated fissure alternately rising from the top to bottom $(t=1083.01 \mathrm{~s}-1106.40 \mathrm{~s})$. The heat further radiates to the center of the rock $(t=1125.32 \mathrm{~s}-1144.51 \mathrm{~s})$ and finally forms a "shear-type" rising temperature field. This indicates that the cracks in the rock block are mainly caused by a shear failure on the left side of the prefabricated fissure, which leads to the constant growth of the temperature field. The temperature field measured on the right side of the rock also shows a trend of rising, but the increasing rate and amplitude are relatively lower than that on the left side. Moreover, the temperature field does not show an obvious surge or dive, which indicates that the new cracks on the right side develop slowly, and no trend of forming a macrofracture surface can be found. By observation, a local abnormal temperature field appears when the rock is approaching the peak stress (i.e., overall rising on the left side). The temperature field of this area tends to experience rapid fluctuation; at the same time, this kind of change appears a certain degree of regularity or synchronicity (such as the temperature alternately rising from top to bottom on the left side of the prefabricated fissure). Therefore, these abnormal temperature changes can be used to judge in advance whether the rock is approaching the ultimate stress or the critical point of failure.

\subsection{Analysis of AIRT Increment under $30 \mathrm{MPa}$ Confining} Stress. Figure 7 shows the temperature change of 25 monitoring regions near the prefabricated fissure under $30 \mathrm{MPa}$ confining stress before approaching the ultimate stress. At $t=773.14 \mathrm{~s}$, the temperature of the whole rock surface pre- sents a step-like distribution with a prefabricated fissure as the boundary line. After maintaining a very short time, because of the weakness of the tip wings, it is easy to accumulate energy and damage and form cracks. The temperature at the left side of tip No. 1 suddenly surges $(t=789.55 \mathrm{~s})$ and then drives the dramatical growth of temperature at region C1 $(t=902.76 \mathrm{~s})$. This indicates the rapid formation of the shear stress field, and it is the development of shear cracks that cause the temperature to rise. Immediately after the formation of the shear fracture at the tip No. $1(t=931.94 \mathrm{~s})$, the temperature drops slightly after energy releasing but still remains at a higher temperature. At the same time, the lower-left area of the prefabricated fissure experiences a transient temperature dive and rise $(t=902.76 \mathrm{~s})$, indicating that the tensional stress field is formed in this area, and the energy dissipation brought by the fracture results in the temperature drop. Subsequently, due to the downward expansion of the shear stress field at the tip of No. 1, the shear crack dominates the failure mode on the left side of the rock surface and leads to the temperature rising slowly again $(t=931.94 \mathrm{~s})$. Meanwhile, a new shear stress field $(t=948.74 \mathrm{~s})$ is formed in region $\mathrm{C} 5$, leading to a gradual increase in the temperature field. In this process, the original ladder distribution gradually transits to a distribution pattern with lower temperature in the middle and high temperature at two tips $(t=965.14 \mathrm{~s})$.

\section{Diffusion Deduction Model of AIRT Increment}

AIRT increment change histogram can intuitively show the change of temperature field before the rock reaching the peak 


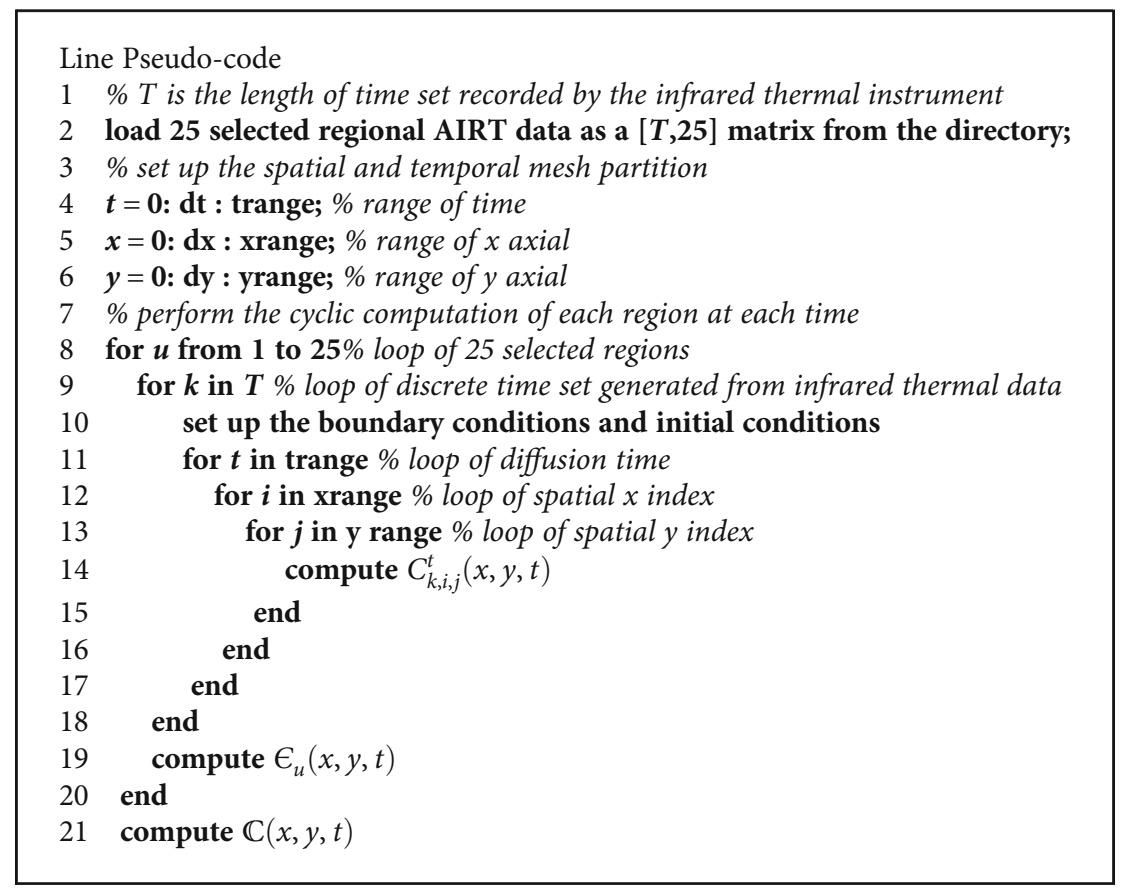

Pseudocode 1: MATLAB Pseudocode.

stress and then obtain the law of damage accumulation and crack diffusion in discrete regions of the rock surface. However, the AIRT incremental histogram cannot well reflect the temperature transition between discrete regions, and it is difficult to intuitively obtain the distribution rule of temperature between regions with large temperature differences. Therefore, this paper introduces the temperature diffusion equation and deduces the real global temperature change.

From Figure 5 to Figure 7, the obtained AIRT is a value that changes by time randomly; thus, $\varphi(x, y, t)$ in Equation (3) is a set of random number but not a clear constant or a function. Additionally, we choose an appropriate "effective coefficient" $D_{e}$ to replace $D_{x}$ and $D_{y}$ in Equation (3) and $\zeta(x, y, t)$ in Equation (4) to do the calculation. Therefore, the form of the heat diffusion equation can be rewritten as

$$
\begin{gathered}
\frac{\partial C_{k}(x, y, t)}{\partial t}=D_{e} \frac{\partial^{2} C_{k}(x, y, t)}{\partial x^{2}} \\
+D_{e} \frac{\partial^{2} C_{k}(x, y, t)}{\partial y^{2}}, \quad k \in T, \\
\left\{\begin{array}{l}
\left.C\right|_{x, y, 0} ^{k}=\varphi_{k}, \quad k \in T \\
\left.\partial C\right|_{x, y, 0}=D_{e}
\end{array}\right. \\
\left.C\right|_{(x, y) \in \partial}=0
\end{gathered}
$$

where $\varphi_{k}$ refers to each discrete temperature at a certain time $k, T$ is the time dataset, and Equation (7) represents the heat diffusion equation of each discrete temperature. Thus, each set of heat diffusion equation will have an explicit difference numerical solution in the form of Equation (6) as follows:

$$
\begin{aligned}
C_{k, i, j}^{t+1}= & C_{k, i, j}^{t}+r x_{e}\left(C_{k, i+1, j}^{t}-2 C_{k, i, j}^{t}+C_{k, i-1, j}^{t}\right) \\
& +r y_{e}\left(C_{k, i, j+1}^{t}-2 C_{k, i, j}^{t}+C_{k, i, j-1}^{t}\right), \quad k \in T,
\end{aligned}
$$

where $r x_{e}=D_{e} d t / d x^{2}$ and $r y_{e}=D_{e} d t / d y^{2}$ are the "effective mesh ratio" in $x$ and $y$ direction. After the temperature field $C_{k, i, j}^{t}(x, y, t)$ is obtained by calculating each set of heat diffusion equations, the global continuous temperature field $\Theta(x, y, t)$ of one region can be obtained by summing up each set of discrete temperatures field:

$$
\epsilon(x, y, t)=\sum_{k=1}^{T} C_{k, i, j}^{t}(x, y, t) .
$$

Through Equations (10) and (11), AIRT diffusion of one selected region is deduced with the discrete temperature changes. Subsequently, by accumulating the AIRT diffusion results of 25 selected regions, the global AIRT diffusion deduction map $\mathbb{C}(x, y, t)$ can be derived as follows:

$$
\mathbb{C}(x, y, t)=\sum_{u=1}^{25} \epsilon_{u}(x, y, t) .
$$

The pseudocode for computing the AIRT diffusion deduction model is listed in Pseudocode 1.

4.1. Analysis of AIRT Increment Conduction under $14 \mathrm{MPa}$ Confining Stress. Figure 8 is the AIRT incremental change diffusion extrapolation map calculated by heat diffusion 

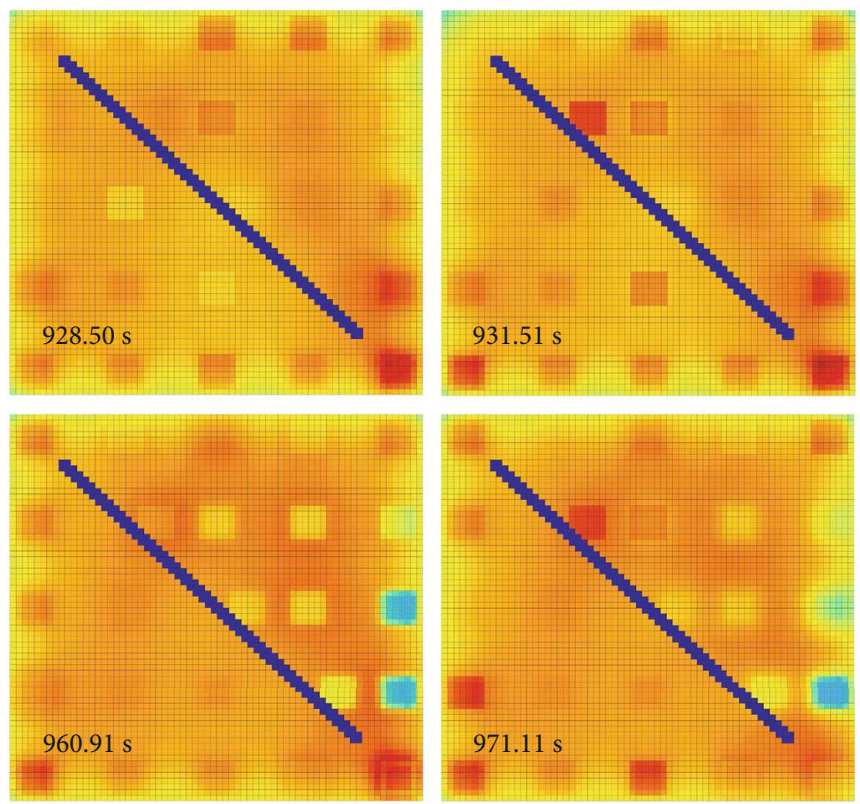

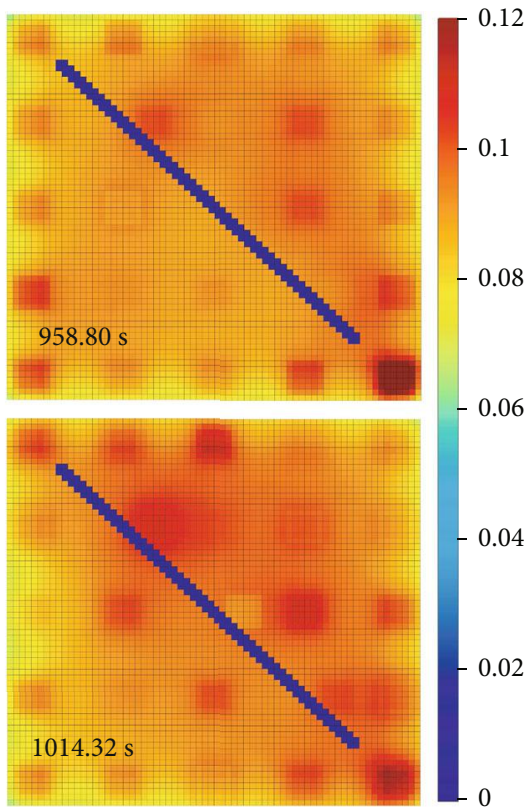

FIGURE 8: Diffusion deduction model of AIRT increment under $14 \mathrm{MPa}$ before peak stress (black line indicates the prefabricated crack), reading from left to right and then up to the bottom.

law. Through the diffusion principle, the temperature around 25 discrete monitoring regions can be simulated and roughly deduced, so as to obtain the global continuous temperature field around the prefabricated fissure. By comparing Figures 5 and 8, it can be found that the temperature change of the two is basically consistent, and the following rules can be summarized from Figure 8. Firstly, when $t=928.50 \mathrm{~s}$, the temperature around the prefabricated fissure is relatively balanced, and the highest temperature is concentrated at tip No. 2. Subsequently, the temperature in the middle of the crack rises $(t=931.51 \mathrm{~s})$, forming a ladder temperature pattern with lower on the left and higher on the right; this indicates that the shear stress field gradually developed along the prefabricated fissure from tip No. 2. After a short time, the temperature at tip No. 2 experiences a sudden soar and fall $(t=958.80 \mathrm{~s}-960.91 \mathrm{~s})$, indicating that the rapid development of cracks and the occurrence of tensile fracture happen near tip No. 2 and highlighting the obvious temperature anomaly. At the same time, the development direction of tensile fracture changes from the bottom to the top, which leads to the decrease of temperature in the upper region of tip No. $2(t=960.91 \mathrm{~s}-971.11 \mathrm{~s})$. After this local temperature anomaly, the temperature of tip No. 2 rises steadily again, which leads to a gradual rise of temperature on the right side of the prefabricated fissure $(t=1014.32 \mathrm{~s})$. However, the temperature in the lower left of the rock decreases gradually, and finally, a step-like temperature layout with lower left and higher right is formed before failure. The maximum temperature is still concentrated near the precast fracture and at tip No. 2, indicating that the tensile stress field developed here gradually changes into a shear stress field. Based on the information obtained in Figure 5, the temperature variation around the monitored area can be further understood through the temperature diffusion extrapolation in Figure 8. This kind of deduction will be more accurate with the extension of the deduction time, and the transition between the deduced temperature and the observed temperature will be smoother.

4.2. Analysis of AIRT Increment Conduction under $22 \mathrm{MPa}$ Confining Stress. Figure 9 shows the diffusion deduction model of AIRT increment change before peak stress under $22 \mathrm{MPa}$ confining stress. It is easy to know from observation that the temperature change law of Figure 6 coincides with that of Figure 9. Through the deduction of Figure 9, it can be found that when $t=1053.30 \mathrm{~s}$, the high temperature is mainly concentrated at tip No. 1, and the global temperature is relatively low. Subsequently, the temperature near tip No. 1 gradually increases $(t=1074.61 \mathrm{~s})$ and gradually spreads to the left side of the precast crack $(t=1083.01 \mathrm{~s})$, pulling up the temperature on the left side. The temperature on the left side gradually rises alternately from top to bottom $(t=1106.40 \mathrm{~s})$. In this process, the overall temperature rises steadily (except for the lower left where there is a temperature surge when $t=1125.32 \mathrm{~s}$ ) and finally formed a temperature layout with high temperature on the left and low temperature on the right $(t=1144.51 \mathrm{~s})$. The highest temperature appears on the bottom left of the rock surface before failure. According to the temperature deduction results, it can be found that the rock sample firstly forms a shear stress field at tip No. 1, with the increase of external load, the shear stress field gradually develops to the bottom and the middle of the rock surface. The overall temperature gradually rises, and the shear stress field finally dominates the left side of the whole rock surface. During this process, there is no significant temperature anomaly, and the overall failure law is presented as the steady development and expansion of shear stress field, indicating that the rock sample has not undergone significant 

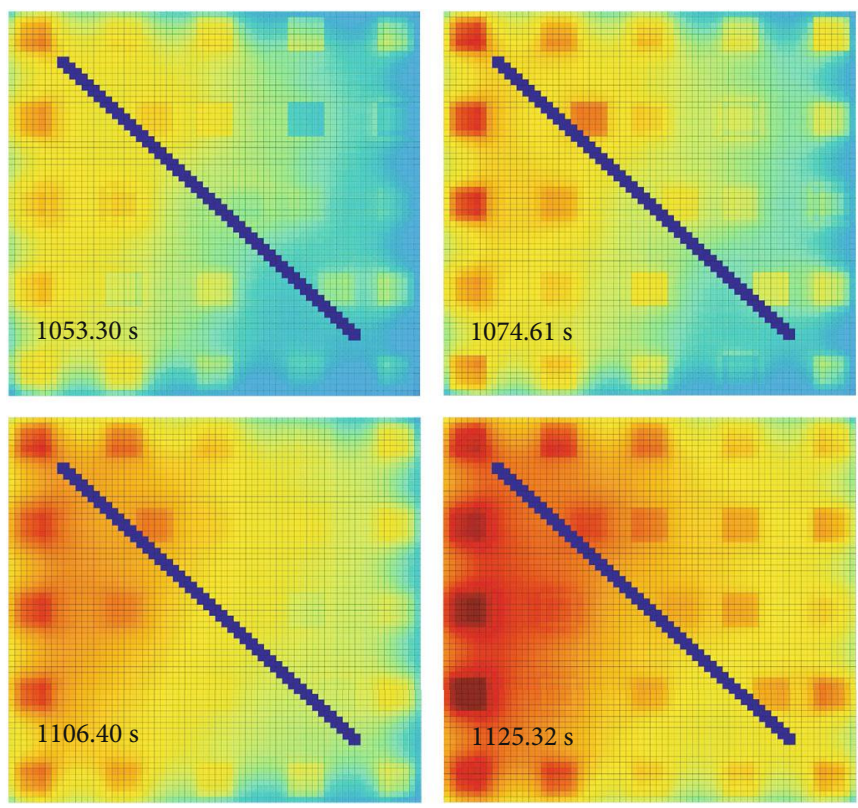
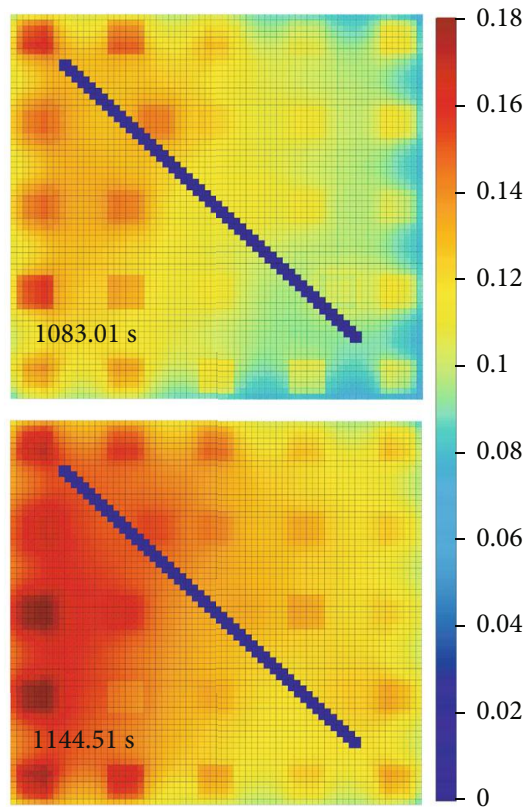

FIGURE 9: Diffusion deduction model of AIRT increment under $22 \mathrm{MPa}$ before peak stress (black line indicates the prefabricated crack), reading from left to right and then up to the bottom.

fracture, and the microshear cracks do not form macroscopic fault zone. This is related to the increase of confining stress that leads to an increase in the overall strain energy capacity of the rock sample. The deduction result agrees with the information provided by the real temperature monitoring data in Figure 6, which also indicates the feasibility of this deduction method.

\subsection{Analysis of AIRT Increment Conduction under $30 \mathrm{MPa}$} Confining Stress. Figure 10 is the AIRT increment change diagram of the rock sample under $30 \mathrm{MPa}$ confining stress. According to the deduced results, it can be found that when $t=773.14 \mathrm{~s}$, the overall temperature near the precast crack is low, and the temperature at tip No. 1 shows the tendency to rise. Subsequently, a sudden increase in temperature $(t=789.55 \mathrm{~s})$ occurs at the left of tip No. 1, which gradually leads to a continuous temperature rise around tip No. 1 $(t=902.76 \mathrm{~s})$ and a gradual heat diffusion to the middle and lower part of the fissure $(t=931.94 \mathrm{~s}-948.74 \mathrm{~s})$. At the same time, a temperature surge $(t=931.94 \mathrm{~s})$ occurs at tip No. 2, which leads to a gradual rise of the temperature near tip No. 2 and spreads to the middle of the rock. Finally, before the rock reaches its peak strength, the overall temperature near the prefabricated fissure forms a ladder pattern which is presented as the higher at the tips and the lower in the middle ( $t=965.14 \mathrm{~s}$ ), and the highest temperature is concentrated near two crack tips. From the above phenomenon, it is not difficult to see that with the increase of confining stress, the storage capacity of elastic energy increases gradually. Before reaching the peak stress, there is no obvious temperature anomaly (except for the left side of tip No. 1 when $t=789.55 \mathrm{~s}$ ), and the overall temperature shows a rising trend, indicating the stable development and expansion of the shear stress field. This law is also highly consistent with the temperature change law in Figure 7, which indicates that the diffusion model proposed in this paper is also applicable under high confining stress.

Through the analysis of triaxial compression experimental data under three groups of different confining stress, it can be found that the AIRT/stress-time curve diagram can be used to observe and analyze the temperature anomaly of some key points, while the temperature analysis of the rest regions is barely feasible. At this point, combined with AIRT increment histogram, the global temperature field changes can be roughly analyzed, and then, the crack initiation, closure, development, propagation rule, as well as the energy accumulation, loss, and dissipation mechanism can be analyzed. After the introduction of the AIRT diffusion deduction model, the temperature change around the monitoring region can be further derived. By deducing the global continuous temperature field, the temperature evolution law before rock fracture can be analyzed in a more detailed and accurate way, and then, the development and propagation law of cracks can be further inferred. From the observation of the thermography, cracks normally evolve from the tips of the fissure firstly and propagate along the direction of the loading orientation; this agrees with the $3 \mathrm{D}$ preembedded crack experiment results from several researchers that the "primary cracks" extended from the initial flaw to the edge of block perpendicular to the compressive load [18-20]; alongside the "primary crack," there exist many petal type cracks caused by shear friction and tensile stress [25, 26]. Anderson also support this conclusion from the view of fracture mechanics, that is, the sharp tips can greatly enlarge the stress concentration effect due to larger length/width ratio of the prefabricated fissure [27]. Compared with our thermography analysis, during the compression, high AIRT anomaly begins at the tips and ends up as locally abnormal 

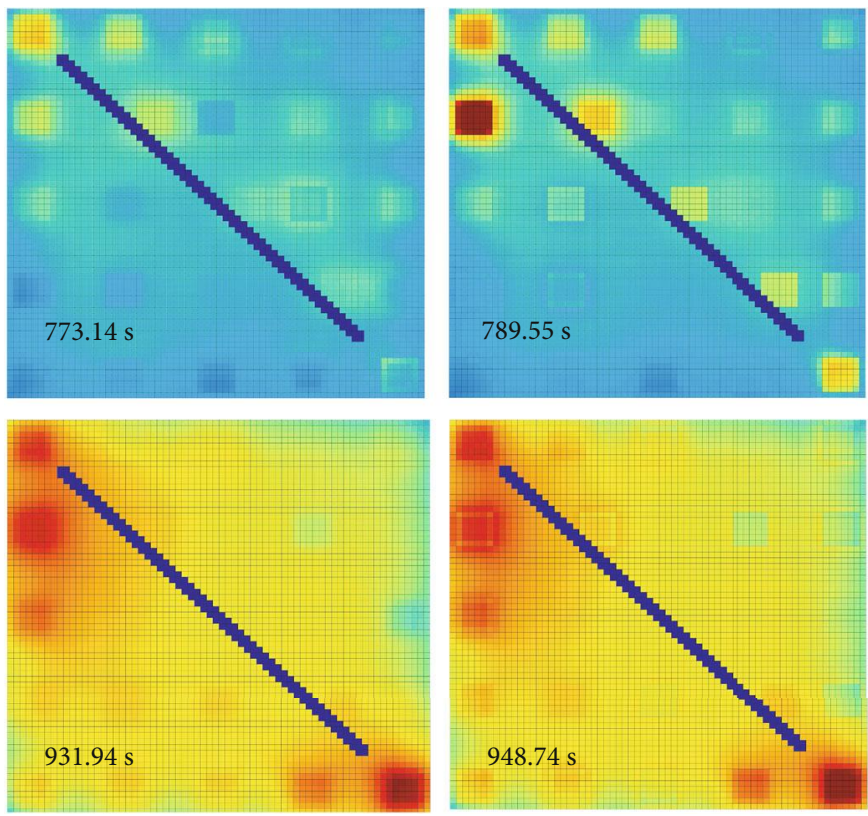
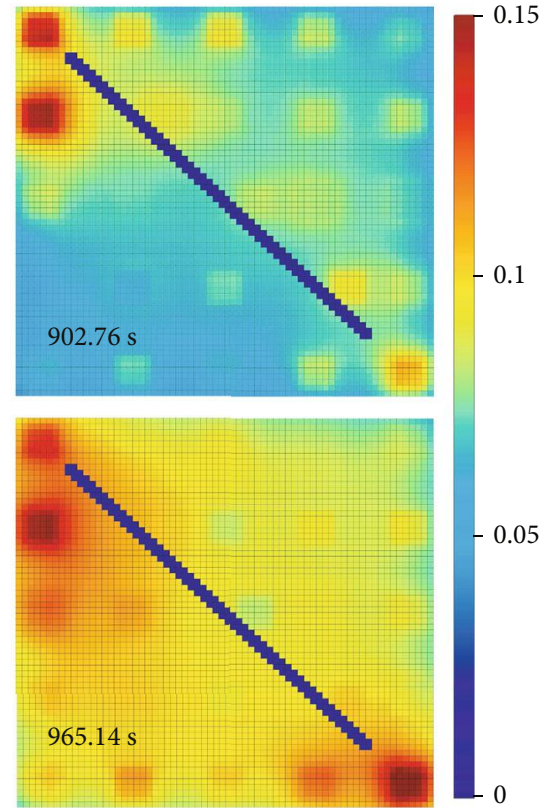

FIGURE 10: Diffusion deduction model of AIRT increment under $30 \mathrm{MPa}$ before peak stress (black line indicates the prefabricated crack), reading from left to right and then up to the bottom.

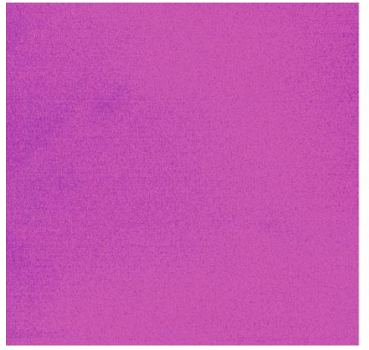

Original thermography

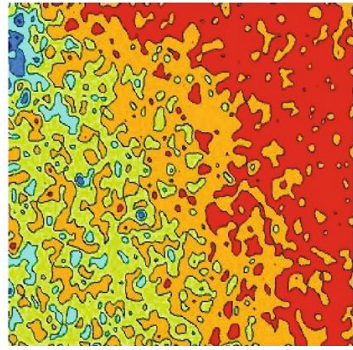

Reproduced cloud map

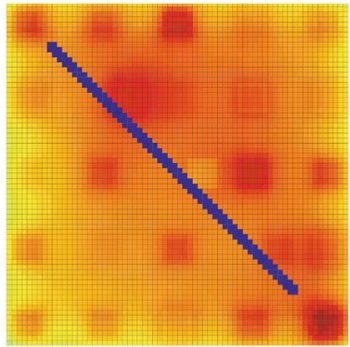

Diffusion deduced model

FIGURE 11: Comparison of original infrared map and the diffusion deduced model at peak stress $(t=1014.32 \mathrm{~s})$ under $14 \mathrm{MPa}$.

temperature along the prefabricated fissure. These AIRT anomaly can be explained by the formation of wing cracks ready to penetrate the block or the petal cracks concentrated around the tips [28-31].

Furthermore, it can be seen from the observation that under lower confining stress, if the rock block has local temperature abrupt change (sudden increase or sudden drop), it means that the rock block will soon reach the peak stress and undergo macroscopic failure. Under the medium confining stress, if the local temperature of the rock block continues to rise and forms an obvious temperature gap among regions, the rock block is likely to reach the peak stress due to steady accumulation of strain energy and damage, but the macroscopic failure will not occur immediately. When under the high confining stress, the rock block has high strain energy storage capacity and high postpeak stress, so the failure and instability of the rock block usually lag behind the arrival of the peak stress. The diffusion deduction model may not be applicable to accurately foresee the failure of the rock block under high confining stress.
4.4. Comparison of the Original Thermography and the Diffusion Deduced Model. Since the conformity between the AIRT increment histograms obtained by the real selected data and the diffusion deduced models has been verified, the next step is to clarify the difference between the original infrared image obtained by the infrared instrument and the deduction model derived from the diffusion law. Figure 11 provides the comparison at peak stress under $14 \mathrm{MPa}$ confining stress, the original infrared thermography can be barely recognized due to lower resolution and precision. Hence, this paper uses MATLAB to generate the reproduced cloud map of the original map to highlight the temperature difference. The diffusion deduction model accords with the original thermography to some extent as they all present a step-like distribution with lower left-side and higher right-side. Additionally, unlike the reproduced cloud map with obvious layer distribution, the deduction model can present subtle temperature transition as the minor conduction and transition within the observed region are demonstrated clearly. Meanwhile, the reproduced cloud map may be influenced by the environment noise in 
the original data, but the diffusion deduction results can eliminate the problem of noise and blur. The diffusion deduced model with "zero-noise and blur" property prevails over the original data and the regenerated cloud map.

\section{Conclusions}

(1) Before the rock sample reaches the ultimate stress under the true triaxial compression test, the AIRT increment at different spots around the prefabricated fissure presents a sudden "drop and surge" phenomenon, indicating that the region around the fissure or cracks is in complex deformation and stress concentration state

(2) The thermal diffusion results of the temperature field on the rock surface show that the abnormal changes of the temperature field (the sudden increase or decrease of the selected regions) usually occur earlier than the peak stress of the rock under low confining pressure, which can better predict the macroscopic failure of the rock in advance. However, under higher confining pressures, the abnormal changes of temperature field are not conspicuous and obvious temperature anomaly may be lag behind the arrival of peak stress

(3) Compared with the temperature variation of the selected regions in the infrared field, the introduction of the heat diffusion deduction model can clearly and effectively display the initiation, development, and propagation process of the crack as well as the corresponding energy dissipation law, which can further promote the application of thermal infrared monitoring method in the prediction of surrounding rock deformation and fracture

\section{Data Availability}

There is no data availability statement.

\section{Conflicts of Interest}

The authors declare that they have no conflict of interest.

\section{Acknowledgments}

This research was supported by the Joint Program between National Natural Science Foundation of China and Shandong Province (U1806209) and Fundamental Research Funds for the Central Universities (TP-19-021A3 and FRFIDRY-19-002) and The Opening Funds of State Key Laboratory of High-Efficient Mining and Safety of Metal Mines (No. ustbmslab201905).

\section{Supplementary Materials}

The supplementary file provides all strength and thermography data, which is reflected as AIRT increment/stress-time curves processed by Origin 2019b. (Supplementary Materials)

\section{References}

[1] M. C. He, J. L. Miao, and J. L. Feng, "Rock burst process of limestone and its acoustic emission characteristics under true-triaxial unloading conditions," International Journal of Rock Mechanics and Mining Sciences, vol. 47, no. 2, pp. 286-298, 2010.

[2] M. P. Luong, "Infrared thermovision of damage processes in concrete and rock," Engineering Fracture Mechanics, vol. 35, no. 1-3, pp. 291-301, 1990.

[3] K. Cao, L. Ma, Y. Wu, N. M. Khan, and J. Yang, "Using the characteristics of infrared radiation during the process of strain energy evolution in saturated rock as a precursor for violent failure," Infrared Physics \& Technology, vol. 109, p. 103406, 2020.

[4] Y.-F. Dong, L.-G. Wang, X.-F. Liu, and L. Dai, "The experimental research of the infrared radiation in the process of rock deformation," ROCK AND SOIL MECHANICS-WUHAN-, vol. 22, pp. 134-137, 2001.

[5] L. Wu and J. Wang, "Infrared radiation features of coal and rocks under loading," International Journal of Rock Mechanics and Mining Sciences, vol. 35, no. 7, pp. 969-976, 1998.

[6] Z. LI, S. YIN, Y. NIU et al., "Experimental study on the infrared thermal imaging of a coal fracture under the coupled effects of stress and gas," Journal of Natural Gas Science and Engineering, vol. 55, pp. 444-451, 2018.

[7] X. Sun, H. Xu, M. He, and F. Zhang, "Experimental investigation of the occurrence of rockburst in a rock specimen through infrared thermography and acoustic emission," International Journal of Rock Mechanics and Mining Sciences, vol. 93, pp. 250-259, 2017.

[8] D. Zhao, S. Zhang, Y. Zhao, and M. Wang, "Experimental study on damage characteristics of granite under ultrasonic vibration load based on infrared thermography," Environmental Earth Sciences, vol. 78, no. 14, p. 419, 2019.

[9] L. Wu and J. Wang, "Features of infrared thermal image and radiation," Science in China Series D: Earth Sciences, vol. 41, no. 2, pp. 158-164, 1998.

[10] H. Sun, X. Liu, S. Zhang, and K. Nawnit, "Experimental investigation of acoustic emission and infrared radiation thermography of dynamic fracturing process of hard-rock pillar in extremely steep and thick coal seams," Engineering Fracture Mechanics, vol. 226, p. 106845, 2020.

[11] L. Wu, S. Liu, Y. Wu, and H. Wu, "Changes in infrared radiation with rock deformation," International Journal of Rock Mechanics and Mining Sciences, vol. 39, no. 6, pp. 825-831, 2002.

[12] J. Huang, S. Liu, Q. Ni, W. Mao, and X. Gao, "Experimental study of extracting weak infrared signals of rock induced by cyclic loading under the strong interference background," Applied Sciences, vol. 8, no. 9, p. 1458, 2018.

[13] M. Imran, H. M. Nick, and R. J. Schotting, "Application of infrared thermography for temperature distributions in fluidsaturated porous media," Arabian Journal of Geosciences, vol. 9, no. 4, p. 318, 2016.

[14] W. Gong, M. He, H. Yan, L. Li, and X. Xu, "Geomechanical model tests and infrared detection of rock responses for tunnels excavated in sedimentary rocks," Procedia Engineering, vol. 191, pp. 20-30, 2017.

[15] M. C. He, W. L. Gong, H. M. Zhai, and H. P. Zhang, "Physical modeling of deep ground excavation in geologically horizontal strata based on infrared thermography," Tunnelling and Underground Space Technology, vol. 25, no. 4, pp. 366-376, 2010. 
[16] H. Sun, L. Ma, N. Adeleke, and Y. Zhang, "Background thermal noise correction methodology for average infrared radiation temperature of coal under uniaxial loading," Infrared Physics \& Technology, vol. 81, pp. 157-165, 2017.

[17] M. N. Ã-Zisik, M. N. Özişik, and M. N. Özisik, Heat Conduction, John Wiley \& Sons, 1993.

[18] M. ADAMS and G. SINES, "Crack extension from flaws in a brittle material subjected to compression," Tectonophysics, vol. 49, no. 1-2, pp. 97-118, 1978.

[19] L. N. Germanovich, R. L. Salganik, A. V. Dyskin, and K. K. Lee, "Mechanisms of brittle fracture of rock with pre-existing cracks in compression," Pure and Applied Geophysics, vol. 143, no. 1-3, pp. 117-149, 1994.

[20] A. Dyskin, E. Sahouryeh, R. Jewell, H. Joer, and K. Ustinov, "Influence of shape and locations of initial 3-D cracks on their growth in uniaxial compression," Engineering Fracture Mechanics, vol. 70, no. 15, pp. 2115-2136, 2003.

[21] D. V. Widder, The Heat Equation, Academic Press, 1976.

[22] Q. Sun, C. Lü, L. Cao, W. Li, J. Geng, and W. Zhang, "Thermal properties of sandstone after treatment at high temperature," International Journal of Rock Mechanics and Mining Sciences, vol. 85, pp. 60-66, 2016.

[23] K. S. Essa, A. Mina, and M. Higazy, "Analytical solution of diffusion equation in two dimensions using two forms of Eddy diffusivities," Romanian Journal of Physics, vol. 56, pp. 12281240, 2011.

[24] B. Noye and H. Tan, "Finite difference methods for solving the two-dimensional advection-diffusion equation," International Journal for Numerical Methods in Fluids, vol. 9, no. 1, pp. 7598, 1989.

[25] T. Zhou, J. B. Zhu, Y. Ju, and H. P. Xie, "Volumetric fracturing behavior of $3 \mathrm{D}$ printed artificial rocks containing single and double 3D internal flaws under static uniaxial compression," Engineering Fracture Mechanics, vol. 205, pp. 190-204, 2019.

[26] J. Zhu, T. Zhou, Z. Y. Liao, L. Sun, X. B. Li, and R. Chen, "Replication of internal defects and investigation of mechanical and fracture behaviour of rock using $3 \mathrm{D}$ printing and $3 \mathrm{D}$ numerical methods in combination with X-ray computerized tomography," International Journal of Rock Mechanics and Mining Sciences, vol. 106, pp. 198-212, 2018.

[27] T. L. Anderson, Fracture Mechanics: Fundamentals and Applications, CRC press, 2017.

[28] J.-W. Fu, K. Chen, W.-s. Zhu, X.-z. Zhang, and X.-j. Li, "Progressive failure of new modelling material with a single internal crack under biaxial compression and the 3-D numerical simulation," Engineering Fracture Mechanics, vol. 165, pp. 140-152, 2016.

[29] Y. Lu, L. Wang, and D. Elsworth, "Uniaxial strength and failure in sandstone containing a pre-existing 3-D surface flaw," International Journal of Fracture, vol. 194, no. 1, pp. 59-79, 2015.

[30] R. Wong, C. Law, K. Chau, and W.-S. Zhu, "Crack propagation from 3-D surface fractures in PMMA and marble specimens under uniaxial compression," International Journal of Rock Mechanics and Mining Sciences, vol. 41, no. 3, p. 360, 2004.

[31] X.-P. Zhou, J.-Z. Zhang, and L. N. Y. Wong, "Experimental study on the growth, coalescence and wrapping behaviors of 3D cross-embedded flaws under uniaxial compression," Rock Mechanics and Rock Engineering, vol. 51, no. 5, pp. 13791400, 2018. 